\title{
CORRIENTES DEL PENSAMIENTO EN AL-ANDALÚS
}

Josep Puig Montada

RESUMO - Três tendências principais do pensamento islâmico - a teologia racional, a filosofia e o sufismo - desenvolveram-se na Península Ibérica durante o domínio árabe. Todas elas tiveram origem no Leste Islâmico e incorporaram pensadores judeus que viviam em al-Andalus. As relações entre essas tendências foram por vezes conflituosas; mas também foram positivas no caso de pensadores que procuraram harmonizar a filosofia e o sufismo (Avempace e Ibn Tufail) ou a filosofia e a teologia rcional (Averróis e Maimônides).

PALAVRAS-CHAVE - Ibn Masarra. Ibn Hazm. Masla al-Magriti. Avempace. Ibn Tufayl. Averroes. Maimônides.

\begin{abstract}
Three main trends of Islamic thought - rational theology, philosophy and Sufism - developed on the Iberian Peninsula during its Arab domination. All three have their origins in the Islamic East and incorporated Jewish thinkers who lived in al-Andalus. The relations among these main trends were often conflictive, but also positive in the case of thinkers who wanted to harmonize philosophy and Sufism (Avempace, Ibn Tufayl) or philosophy and rational theology (Averroes, Maimonides).
\end{abstract}

KEY WORDS - Ibn Masarra. Ibn Hazm. Maslama al-Magritî. Avempace. Ibn Tufayl. Averroes. Maimónides.

El mundo islámico vive un momento histórico de máximo esplendor en el primer periodo abbasí, en un periodo que va de la primera mitad del siglo VIII a la del siglo IX, cuando su imperio se extendía desde Bukhara, en la Transoxiana actual república de Uzbekistán - hasta el valle del Duero. Desde el califa alManșûr (reinó 754-775) hasta al-Ma'mûn (r. 811-833) los califas abbasíes fomentan el movimiento cultural y científico. ${ }^{1}$ Dos actividades transcurren en paralelo, una, la creación de las ciencias islámicas y la otra, la traducción de obras científicas y filosóficas de la antigüedad greco-helenística, y por esta doble vía, la teología y la filosofía se consolidan en Oriente. ${ }^{2}$ En las ciencias islámicas, Abû Ḥanîfa (m. 767), Mâlik Ibn Ânas (m. 796), as-Shâfieî (m. 820), Ibn Ḥanbal (m. 855) crean las grandes escuelas del derecho islámico; Ibrâhîm an-Naẓ̧âm (m. 846) y Abû l-Hudayl al'Allâf (m. ca. 840) sobresalen entre los teólogos racionalistas. En filosofía, al-Kindî

Universidad Complutense.

Nota sobre las transcripciones: Seguimos el sistema anglo-norteamericano, el más difundido, con la excepción de ج transcrita "g" según la pronunciación egipcia ("gh" transcribe غ̇), para no confundir al lector español.

2 Dimitri Gutas, Greek Thought, Arabic Culture. Londres: Routledge, 1998.

\begin{tabular}{|l|l|l|l|l|l|}
\hline VERITAS & Porto Alegre & v. 52 & n. 3 & Setembro 2007 & p. 55-78 \\
\hline
\end{tabular}


(m. ca. 870), que vive en Bagdad durante los reinados de varios califas, inicia la filosofía islámica en un ambiente de convivencia interreligiosa.

En cambio, en al-Andalús, ni el emirato omeya dependiente de Damasco (711-755) ni el independiente (755-912) pueden compararse con el oriente en esplendor. Tampoco la cultura hispano-visigoda puede compararse en riqueza con el helenismo de Siria, próxima además a Bizancio que, a pesar de las guerras con los árabes, sigue aportando su legado. Es lógico que el desarrollo cultural en alAndalús sea posterior, y tendrá lugar gracias a la comunicación existente dentro del mundo islámico, y al margen de la fragmentación del imperio a partir de la segunda mitad del siglo X. Una misma lengua y una misma religión hacen que personas e ideas se muevan entre territorios tan distantes de manera continuada.

La historia de las ciencias de Abû l-Qâsim Șâiid Ibn Șậid, que vivió en alAndalús, 1029-1070, es una fuente autorizada para conocer el desarrollo de la filosofía y de las otras ciencias antiguas en la España musulmana. Șâid sitúa en la época del emir Muhammad (852-886) el inicio de la actividad, pero en el primer siglo, entre 250-350 Hégira (864-961) menciona solamente tres personajes, conocedores de la aritmética y la astronomía, y siete médicos.

Șâeid excluye de su historia a los sufíes, como también a los mu tazilíes, siguiendo el criterio de considerar "ciencias de los antiguos" las matemáticas con la astronomía - la medicina y la filosofía. Así no incluye en el apartado a Muhammad Ibn Masarra (883-931), el primer místico de importancia conocido, pero lo menciona antes, cuando habla de la ciencia en Grecia. En efecto, Șâcid habla de los cinco filósofos griegos más notables, el primero de los cuales es Empédocles y en su apartado especifica:

Un grupo de batiníes ${ }^{4}$ se apoya en su doctrina y afirma que Empédocles tiene pensamientos misteriosos que raras veces se alcanzan a comprender. El batiní Muhammad 'Abdallâh Ibn Masarra al-Gabalî, natural de Córdoba, estaba entusiasmado con su filosofía y se dedicaba a enseñarla. ${ }^{5}$

El pensamiento de Ibn Masarra fue estudiado primero por M. Asín Palacios, ${ }^{6}$ quien insistió en la afiliación al Pseudo-Empédocles. Asín se basó en Shahrastânî, un heresiógrafo que murió en 1153, dos siglos más tarde que Ibn Masarra, para reconstruir la doctrina de éste, que recogería elementos neoplatónicos, que habían pasado al Islam bien en el conjunto de las traducciones, bien de manera no escrita a través de las gnosis cristianas y que forman parte del bagaje intelectual de los

\footnotetext{
Tabaqât al-umam, ed. Louis Cheikho, Beirut, 1912; ed. Hayât Bû 'Alwân, Beirut, 1985. Trad. francesa R. Blachère, Livre des catégories des nations, París, 1936. Trad. española Felipe Maíllo, Madrid: Akal, 1999. Así mismo, Andrés Martínez Lorca - Eloísa Llavero Ruiz, Historia de la Filosofía y de las Ciencias o Libro de las categorías de las naciones: (Kitâb tabaqât al-umam) Madrid; Trotta, 2000.

4 Batiní' deriva de bâtịn, 'interior' opuesto a zaâhir, 'exterior'. Los shî‘ies, en sus dos ramas, la imâmí y la ismâ îlí, así como los sufíes, sostienen que el Corán tiene dos sentidos, uno esotérico y el otro exotérico, pero generalmente se identifica a los batiníes con los shî‘íes septimanos o ismâ^illíes. Țabaqât al-umam, traducción Maíllo, p. 63.

Abenmasarra y su escuela. Orígenes de la filosofía hispano-musulmana, Madrid, 1914.
} 
sufíes. El mundo es creado por emanación, y las cinco primeras emanaciones son la Materia Primera, el Intelecto, el Alma, la Naturaleza, y la Materia Segunda. Rafael Ramón ha explicado que, en efecto, doctrinas como ésta se encuentran en una obra atribuida a Empédocles en círculos neoplatónicos y conocida por Libro de las cinco sustancias. ${ }^{7}$

La dificultad estriba, sin embargo, en que Asín Palacios reconstruía una doctrina sobre meros indicios, y además aceptaba la afiliación que Șâeîd de Toledo hacía, sin justificar, de Ibn Masarra a Empédocles, error señalado por S. M. Stern. Más tarde se descubrieron y publicaron dos obras atribuidas a Ibn Masarra, ${ }^{8}$ de manera que ahora conocemos mejor lo que Ibn Masarra defendía y que inspiró un movimiento social en la serranía cordobesa.

En una de estas dos obras, Libro de las particularidades de las consonantes, Ibn Masarra - suponiendo sea el verdadero autor - toma las letras misteriosas que se hallan al comienzo de algunas azoras como fundamento y origen de todas las cosas. En la segunda obra conservada, la Epístola de la reflexión, Ibn Masarra declara que el universo es un libro cuyos lectores privilegiados son los amigos de Dios. El conocimiento más excelente se obtiene mediante el corazón, pero no un corazón material, sino espiritual, y gracias a él los amigos de Dios conocen lo oculto y dan testimonio de la Verdad, es decir, de Dios. No parece que nos encontremos con un discípulo del Pseudo-Empédocles sino con un autor esotérico, y precisando más, ismaelí. Además Ibn Masarra es el punto de partida de la rica escuela andalusí de mística y a partir de él la cadena sufí no se interrumpe en alAndalús. El mayor místico musulmán provendrá de esta tradición, será el murciano Muhyî d-dîn Ibn al- `Arabî (1165-1240).

Bajo el califato de al-Ḥakam II (961-976), la situación científica cambió en la península; el califa hizo traer de Bagdad, Egipto, de Oriente, las obras capitales relativas a las ciencias antiguas y a las modernas, y fomentó el estudio de estas ciencias antiguas, es decir, la filosofía y las ciencias helenizantes. Su hijo Hishâm II, sin embargo, dejó que Almanzor, su todopoderoso chambelán, y los alfaquíes expurgaran la biblioteca de todas aquellas obras que no pertenecieran a las ciencias islámicas y de las matemáticas y la medicina, algo que se repetirá en el futuro, incluso cristiano. Tras la desmembración del califato, los libros que se guardaban en palacio, fueron vendidos a precios irrisorios, pero al menos no se perdieron y alguna obra de filosofía habría escapado a los censores. El surgimiento de los reinos de taifas, en todo caso, fue un factor positivo en el desarrollo de las "ciencias de los antiguos"; éstas se cultivan en las distintas cortes, y ceden las

Rafael Ramón Guerrero, "Ibn Masarra, gnóstico y místico andalusí" en: Las raíces de la cultura europea: ensayos en homenaje al profesor Joaquín Lomba coordinados por José Solana Dueso, Elvira Burgos Díaz, Pedro Luis Blasco Aznar. (Zaragoza: 2004), pp. 223-240.

8 Publicadas en El Cairo, 1978, cf. Emilio Tornero Poveda, "Noticia sobre la publicación de obras inéditas de Ibn Masarra" en: Al-Qantara: Revista de estudios árabes, 14:1 (1993) 47-64. 
presiones religiosas contrarias. El propio Șâeid reconoce lo afortunado del momento en que vive.

De este modo, la lista de estudiosos de estas ciencias es bastante considerable a partir de al-Hakam II. La mayoría son científicos, como Abû lQâsim Maslama al-Magrîṭ̂i (muere entre 1005-08), matemático y astrónomo, "el primero de los de su tiempo" y con discípulos destacados ${ }^{9}$ y ya en tiempos de Șâeid, Ibrâhîm Ibn Yaḥyà walad az-Zarqiyâl (m. 1100). Los médicos también abundan; las figuras más interesantes aparecen tarde, ya en vida de Șâeid, por ejemplo, el ministro Ibn Wâfid y Abû Marwân 'Abd al-Malik Ibn Zuhr. Por el contrario, los filósofos, es decir quienes se dedican a la "ciencia de la naturaleza y a la metafísica" son raros ${ }^{10}$ y van muy detrás de los que se dedican a la lógica.

Como expertos en el arte de la lógica, Șâeid destaca a Abû l-Ḥasan Ibn Sîda (-1066) y a Abû Muhammad ‘Alî Ibn Hazm (994-1063), el polígrafo cordobés al que M. Asín Palacios consagró buena parte de sus estudios. ${ }^{11}$ No deja de sorprender que Ibn Hazm aparezca como lógico, pues el propio Șâeid nos advierte que su libro de lógica, Acercamiento a las definiciones de la lógica, "está lleno de errores y faltas evidentes".

Frente a las reticencias que muchos pensadores musulmanes mostraban frente a la lógica griega, Ibn Hazm optó decididamente por ella, porque veía en la misma un medio para reforzar y asegurar argumentos en defensa de dogmas y mandamientos religiosos. El silogismo, con sus formas y modos, es el instrumento ideal para hacer de simples mandatos o prohibiciones, conclusiones de la correspondiente deducción que añade a la fuerza moral que les da la revelación, la fuerza de la razón. Véamos este ejemplo, donde se recurre al silogismo Barbara, de la primera figura y primer modo:

Toda bebida fermentada es ilícita

Toda bebida embriagante es bebida fermentada

Luego toda bebida fermentada es ilícita.

Sin entrar en la crítica de Șâeid, digamos que la lógica de Ibn Hazm está en línea con la tradición islámica medieval, que adopta la lógica aristotélica, en su versión ampliada por Teofrasto (372?-285 a.C.) a los silogismos condicionales. En cuanto a la ampliación que al parecer hizo Galeno (131-201), de una cuarta figura del silogismo, Ibn Hazm es uno de los primeros en rechazarla. Si Ibn Hazm se apoyaba directamente en el Organon de Aristóteles, es algo que no está claro. Veo

\footnotetext{
Ibn as-Samh, Ibn aș-Șaffâr, az-Zahrawî, Ibn Khaldûn, al-Kirmânî; Ibn al-Khayyâț. Varios de ellos eran también médicos.

Al-Ḥammâr, al-Bigâ'î, Ibn Hûd e Ibn Ḥasday, éste era de religión judía.

11 Abenházam de Córdoba y su historia crítica de las ideas religiosas. 4 vols. Madrid, 1931. Reprint Madrid: Turner, 1988.

12 Taqnîb li-ḥudûd al-manțiq, Beirut, 1959. También en Rasâili, Beirut, 1983, pp. 91-356. Cf. Rafael Ramón, "El pensamiento griego en la lógica de Ibn Hazm. Su Kitâb at- taqrîb", en Anales del Seminario de Historia de la Filosofía, 12 (2002) 27-38.
} 
una relación entre este interés, relativo, por la lógica y la escuela jurídico-teológica (madhhab) a la que Ibn Ḥazm se adhiere, la fundada por Dâ'wûd Ibn Khalaf (m.883). La escuela zâhirí, o literal, se pronunciaba por una interpretación al pie de la letra del texto coránico, oponiéndose a los métodos utilizados para obtener sentidos derivados, como eran la analogía (qiyâs) y la opinión (ra'y). Estos eran métodos de la escuela malikí, seguidora de Mâlik Ibn Ânas, muy extendida en alAndalús y cuya fuerza espiritual no puede separarse de la fuerza política de sus alfaquíes.

El uso de la lógica justificaría la lectura literal, permitiendo solamente una aplicación limitada a otras situaciones o tesis no previstas en el texto. Ibn Hazm es tan radical frente a las interpretaciones jurídicas como frente a las especulaciones teológicas del Kalâm, en sus dos ramas, la racionalista de los mu'tazila, considerada heterodoxa, y la ortodoxa, fundada por al-Ash arî (873935) ${ }^{13}$. Abû l-Hasan al-Ash`arî fue mu`tazilí antes de abjurar de esta doctrina y crear su propia escuela, menos racionalista y más tradicional, admitiendo, por ejemplo, que Dios posee atributos distintos de su esencia. Ibn Hazm es un gran conocedor del Kalâm, y es una de nuestras fuentes de información sobre el mismo. Aunque, a menudo, Ibn Hazm se pronuncie en contra de estos teólogos, en particular, de los mu'tazila y sus opiniones no coincidan, es evidente que se está moviendo dentro de las coordenadas del Kalâm. ${ }^{14}$

Ibn Hazm divide la realidad entre el Creador y lo creado; éste a su vez se subdivide entre lo que se sustenta a sí mismo y ocupa un lugar (sustancia) y lo que no se sustenta en sí mismo sino en una sustancia (accidente). La clasificación es común en el Kalâm, pero no la tesis siguiente: "Toda sustancia es cuerpo y todo cuerpo es sustancia. Ambos nombres tienen un mismo y único significado". ${ }^{15}$ En cuanto a la constitución de los cuerpos, la mayoría de los mutakallimíes, tanto mu tazilíes como ash`aríes, se inclinaron por el atomismo. El atomismo nace en Grecia, con Leucipo y Demócrito y no tiene mucha fortuna ni en Grecia ni en el helenismo, solamente Epicuro lo defiende. Por el contrario, el Kalâm ve en él una forma de explicar la naturaleza más conforme con la omnipotencia divina, su acción continuada en la creación frente a la inconsistencia de ésta. Ibn Hazm está muy bien informado, y muy al día pues nos habla incluso de al-Baqillânî (fallece en 1013), pero se inclina por la corriente minoritaria del Kalâm, que entiende que los cuerpos son continuos y pueden dividirse indefinidamente. Esta corriente fue fundada por Ibrâhîm an-Naẓạam (m. 845), e Ibn Hazm la sigue a veces, sabedor por lo demás de que representa la opinión de los antiguos.

Ibn Hazm sigue también a an-Naẓâam en cuanto a la acción causal del hombre. Los mu tazilíes eran partidarios de la responsabilidad humana sobre sus

13 Luciano Rubio, El "ocasionalismo" de los teólogos especulativos del Islam. Ediciones Escurialenses, 1987.

14 R. Arnaldez ya señaló este hecho, Grammaire et théologie chez Ibn Hazm de Cordoue (París: Vrin, 1956), pp. 283-284

${ }^{15}$ Kitâb al-fișal fi l-milal wa-l-ahwâ' wa-n-nịhal, vol. 5 (El Cairo, 1321/1903; rep. 1400/1980), p. 69. Asín, vol. V, pp. 242-243. 
acciones, pero no por ello consideraban que el hombre fuera capaz, sin más, de actuar como la veradera causa. Dios era, en opinión de unos, esta verdadera causa que operaba directamente, en el plano físico, tanto en los fenómenos naturales como en los actos del hombre, quien se hacía responsable a nivel moral. Existe pues un conflicto para mantener estos dos principios, la omnipotencia divina y la responsabilidad humana, pero también hay que dar una explicación razonable de las relaciones causales entre los seres de la naturaleza, y en particular de las acciones humanas sobre el mundo externo.

Para ello, algunos mu tazilíes desarrollaron la teoría de la "generación", tawallud. Así quienes la suscriben, establecen que el hombre no sólo es capaz de acciones "directas" sino también de producir efectos mediatos, que salen de sí mismo, y el ejemplo de la piedra o la flecha que una vez disparada, sigue en movimiento, ilustra esta interpretación. An-Naẓâm va más lejos en esta formulación de la causalidad: Dios ha creado en los seres una naturaleza propia (khilqa, tab') que también es necesaria para producir el efecto. La piedra o la flecha reciben de Dios una disposición para moverse por el aire, y el efecto se genera por conjunción del agente y de esta naturaleza. De manera consecuente, extiende la causalidad también a las criaturas distintas del hombre. Como observaría al-Ghazâlî, mejor conocido por Algacel (1111), esta doctrina del tawallud acerca a los mu tazilíes a los filósofos, y an-Naẓạâm es el más próximo. Ion Hazm también está cerca de esta postura cuando dice:

La dependencia (iḍ̂fa) de todo fenómeno cósmico respecto de Dios es distinta de la dependencia que tiene con aquello de lo que se ve que procede. Su dependencia de Dios es porqué lo creó, mientras que su dependencia con aquello de lo que se ve que procede o ha sido generado (tawallud) es por hecho de la procedencia, de acuerdo con lo que testimonian el Corán y todas las lenguas y tradiciones del profeta... Ambas dependencias son reales y no metafóricas. ${ }^{16}$

En el caso del hombre, además, Dios crea la capacidad de elección (ịhtiyâr), que le hace responsable de sus acciones. En definitiva, el pensamiento de Ibn Hazm se mueve dentro del Kalâm: en materias estrictamente teológicas, su literalismo no impide que siga a al-Ash`arî; en la explicación global del funcionamiento del mundo, sigue a los rivales mu`tazilíes y la sintonía con anNaẓâam deja sentirse.

La relación de Ibn Hazm con la filosofía es compleja. Acepta la lógica y rechaza la física y metafísica. Como prueba de lo primero recordemos la mencionada obra de lógica y añadamos otra, una clasificación de las ciencias y, como prueba de lo segundo, una refutación de al-Kindî ${ }^{17}$ y otra refutación de Zakarîyâ ar-Râzî (m. entre 925-932) no conservada. En un sentido más general del concepto de filosofía, la admite como ética:

Fișal, vol. II.5, p. 60. Traducción de Asín, Abenházam, tomo 5, pp. 225-226.

Ar-radd 'alà al-Kindî al-failasûf, en sus Rasâ'il Ibn Ḥazm, ed. Iṇsân Abbâs (Beirut, 1983), pp. 361406. 
La filosofía... no es otra cosa que la corrección o mejora del alma humana, conseguida, ya por medio de la práctica de las virtudes morales y de la buena conducta en esta vida para alcanzar en la otra la salvación, ya por medio de una buena organización social, así doméstica como política. ${ }^{18}$

Ibn Hazm afirma, e insiste una y otra vez, que el Corán y los hadices auténticos son la única fuente normativa. La ley religiosa o sharîa, está expresada en la palabra divina o Corán y el musulmán debe entender el Corán en su sentido literal. Ibn Hazm sigue la escuela zâhirí, rechaza el principio de analogía que le permitiría interpretar el texto sagrado con más libertad. No está dispuesto más que aceptar el consenso, pero en condiciones limitadas, es decir, un consenso unánime entre los compañeros inmediatos del Profeta.

Hacer de la revelación la base de toda la normativa presupone el reconocimiento del Corán como revelado por Dios a Mahoma, y que éste es su último profeta ¿Cómo sabemos, pues, que la revelación, básicamente el Corán, es auténtica?

Parece que Ibn Hazm se basa en los milagros como prueba de la autenticidad del Corán, y lo hace de una manera tan radical que poco espacio deja para la razón. Destaca que Mahoma dio de beber a su ejército sediento en Tabûk y en Hudaibîya haciendo un milagro: el agua manaba de un vaso que sostenía en su mano. Mahoma dio de comer milagrosamente a su ejército en la batalla de la Trinchera y en casa de Gâbir. Arrojó un puñado de arena contra la tribu de Hawâzin y los cegó a todos. El milagro más extraordinario, sin embargo, es el carácter único del Corán. Aunque Mahoma retó a sus contemporáneos a que compusieran una obra parecida, ninguno fue capaz, pues todos sabían muy bien que no poseían la inspiración divina necesaria. ${ }^{19}$

Ibn Hazm no duda de la autenticidad ni de los milagros descritos en los hadices porque la cadena de los transmisores es correcta y, en cuanto a la unicidad del Corán, no concibe otra explicación que su carácter milagroso. Podemos decir que utiliza algo de la razón - sus argumentos tienen cierta plausibilidad - para negar la razón como base de la fe. Para Ibn Hazm, la fe no es más que aquello que Dios ha denominado fe, ni infidelidad más que aquello que Dios denomina infidelidad. No existe una fundamentación objetiva de lo que es bueno o malo, solamente la fe nos lo dice, y antes de la revelación a Mahoma,

No había ninguna inteligencia en la que lo bueno fuera bueno, ni lo malo, malo, así como no existía ningún alma, intelectiva o no, en la cual lo bueno fuera hecho bueno o lo malo, malo... hasta que Dios creó las almas, las dotó de entendimientos creados y Dios hizo malo lo que hizo malo, e hizo bueno lo que hizo bueno. ${ }^{20}$

Fișal, vol. 1, p. 94. Trad. Asín, Abenházam, tomo 2, pp. 205-206.

Fișal, vol. 1, pp. 104-107. Trad. Asín, Abenházam, tomo 2, pp. 220-224. Cf. vol. 5, p. 7.

Fișal, vol. 3, p. 100. Trad. Asín, tomo 4, p. 9. 
En consecuencia, las virtudes y los vicios no están definidos por la realización de actos buenos o malos, sino por obedecer o desobedecer los mandamientos de Dios, cuya voluntad suma todas las virtudes. En palabras del propio Ibn Hazm: "No hay más virtud que la obediencia a lo que Dios ordena o insta, ni más vicio que perpetrar aquello que Dios ha prohibido o declarado pecaminoso" ${ }^{21}$

Ibn Ḥazm es el representante más notable de la teología musulmana, del Kalâm y para un contemporáneo de altura equiparable, debemos buscarlo en Irán. Abû l-Ma'âlî 'Abd al-Malik al-Guwainî (1028-1085), ${ }^{22}$ el Imâm al-Ḥaramain, consolidó el Kalâm de manera expositiva y apta para la enseñanza; Ibn Ḥazm, con un estilo menos escolar, no tuvo gran éxito ni una escuela que siguiera sus enseñanzas.

Al-Andalús permanece en contacto con Oriente, aunque como vemos recibe con cierto retraso muchas doctrinas. En la segunda mitad del siglo X, en Basora actúa un grupo de pensadores organizados en una forma que nos recuerda los círculos de los pitagóricos: son los llamados Hermanos de la Pureza. Uno o varios son autores de una enciclopedia del saber de los antiguos ${ }^{23}$ con temas muy diversos: elementos de filosofía aristotélica, neo-platónica, pitagórica, astrología, matemáticas, música, etc. Șâ‘id, a quien me he referido en otras ocasiones, nos dice que un matemático andalusí con un gentilicio persa, al-Kirmânî, Abû l-Ḥakam 'Amr, natural de Córdoba viajó hasta Ḥarrân - el centro sabeo - y regresó de Oriente con las Epístolas de los Hermanos de la Pureza. La noticia debemos leerla con reservas, pero es cierto que al-Kirmânî se instaló en Zaragoza donde murió a los 80 años, en $1066 .^{24}$

Las huellas de las Epístolas aparecen en al-Andalús en un tratado astrológico y mágico, atribuido falsamente al matemático Maslama al-Magrị̂̂î, y que en la traducción alfonsina se llama Picatrix (Buqrâțîs). El título exacto es Objetivo del sabio y los dos resultados [alquimia y magia] que merecen ofrecerse, ${ }^{25}$ y según Ritter, se compuso en la época de guerras civiles en Córdoba, 1041-1051. No sabemos si la difusión de este saber es una contribución real a la de la filosofía, pero sí se considera un saber antiguo a pesar de los elementos hindúes e islámicos agregados, entre los que figuran ya textos de al-Fârâbî. ${ }^{26}$ Sin embargo, la Enciclopedia de los Hermanos de la Pureza abarcaba otras materias, más

${ }^{21}$ Al-ịkâm li-uṣûl al-aḥkâm. Ed. A.M. Shâkir, El Cairo, 1345-48/1926-28; reimpreso, con una introducción de I. 'Abbâs, 8 vols. en 2 tomos, Beirut, 1983. Aquí, Ị̣kâm, vol. 1, p. 5.

22 Para su biografía, véase la introducción de Paul E. Walker, el traductor del Irshâd: A Guide to Conclusive Proofs for the Principles of Belief. Garnet 2000.

23 Rasấil Ikhwân aș-Ṣafâ'. Ed. B. Bustanî, 4 vols. Cairo, 1928, R Beirut: Dâr Sâdir s.a. Bibliografía actualizada en la tesis doctoral de Ricardo F. Albert, Universidad Complutense, 2002.

${ }^{24}$ Tabaqât, trad. Maíllo, pp. 129-130.

25 Ed. Hellmut Ritter, 1933. Traducción española de Marcelino Villegas, Picatrix, Madrid: Editora Nacional, 1983

${ }^{26}$ Rafael Ramón, en su artículo "Textos de al-Farabi...", Al-Qanțara 12 (1991), pp. 3-17, demuestra que textos de al-Fârâbî (m. 950) aparecen ya en la obra. 
relacionadas con la filosofía. Así el pacense Ibn as-Sîd (1063-1127) aprovechó de ella partes neo-platónicas, y también pitagóricas, en su Libro de los cercos. ${ }^{27}$

La filosofía en sentido estricto, Falsafa, hace su entrada oficial de la mano de Abû Bakr Ibn aș-Șâeigh Ibn Bâgga, conocido entre nosotros por Avempace, y que han editado y estudiado M. Asín Palacios, ${ }^{28}$ y recientemente, Joaquín Lomba. ${ }^{29}$ Avempace nació entre 1085-90, en Zaragoza, donde vivió hasta 1118, cuando los cristianos tomaron la ciudad. Empezó entonces una emigración por la península, al servicio de los almorávides, pasando luego a Orán y Fez. Allí murió envenenado en una fecha imprecisa, entre 1128 y 1138.

Mientras Ibn Hazm vivía la desintegración del califato y la aparición de los reinos de taifas, Avempace vive el fin de éstos y la llegada de los refuerzos almorávides, que no logran frenar el avance cristiano. Así crece y se educa en la Zaragoza capital de la taifa de los Banû Hûd, reino que desaparece en 1110 con la llegada de los almorávides. El gobernador almorávide Ibn Tifilwît aprecia las cualidades de Avempace, quien aparece como visir en su corte. La caída de la ciudad pone fin a esta etapa afortunada de su vida.

Avempace es fruto de la sociedad andalusí, que, a pesar de la debilidad política, goza de una gran vitalidad cultural. Su formación es variada: es médico, botánico, astrónomo, lógico... Conoce directamente las obras de Aristóteles, y es el primero en escribir comentarios a las mismas destacando "por su acierto en la comprensión". Ibn al-Imâm afirma que después de al-Fârâbî no habido otro pensador como Avempace, por delante de Avicena y de Algacel. Ni Avicena ni su adversario Algacel - incompatibilidad que parece desconocer Ibn al-Imâm - van a tener tanta influencia como él.

En efecto, al-Fârâbî, o Alfarabi, juega un papel esencial de éste en el pensamiento andalusí, en particular como lógico y filósofo del lenguaje. La obra más difundida de Alfarabi es el Libro de las opiniones de los habitantes de la ciudad virtuosa y obra la mejor conocida de Avempace, Régimen del solitario, ${ }^{30}$ se inspira en ella. Avempace comienza examinando el sentido de 'régimen' como ordenación de actos para un fin. En sentido absoluto, el régimen es político y ordena la vida de los ciudadanos para alcanzar su perfección. Avempace sigue a Platón, y quizá lo hace solamente a través de la versión de Alfarabi, en la descripción de la ciudad ideal y de las cuatro clases de sociedad - ciudades imperfectas o enfermas.

El filósofo no puede vivir en estas ciudades enfermas y debe emigrar, pero la emigración es interior y este emigrante es el solitario. Éste tiene que vivir dentro de ciudades enfermas, pero sintiéndose libre de sus luchas y persiguiendo un

\footnotetext{
M. Asín Palacios, "El libro de los cercos", Al-Andalús 5 (1940) 45-152.

"El filósofo zaragozano Avempace" en Revista de Aragón 1 (1900), 2 (1901) 241-46; 301-03; 348-50.

Avempace, Zaragoza: Diputación General, 1989. La filosofía islámica en Zaragoza, Zaragoza: Diputación General, 1991, 2ª ed.

30 Edición y traducción M. Asín Palacios, Madrid-Granada, 1946. Nueva traducción de Joaquín Lomba, Madrid: Trotta, 1997.
} 
ideal. Podemos comprender mejor lo que nos dice Avempace, si pensamos en su vida errante y en su triste final.

La realización del ideal del solitario está en la vida teorética. Su base está en una división de la realidad en material y espiritual, y dentro de esta en una jerarquía de "formas espirituales": primero, las formas de los cielos, segundo, el entendimiento agente (y el adquirido), tercero, los inteligibles abstraídos de la materia, cuarto, las formas, literalmente, significados, ma'ânî, que nos proporcionan el sensorio común, la imaginación y la memoria. La primera clase es totalmente inmaterial, siguiendo la tradición que considera las esferas celestes inteligencias. El entendimiento agente produce y el entendimiento adquirido recibe unas formas que aunque no son materiales, mantienen una relación con los inteligibles materiales de la tercera clase. Esta tercera clase son unas "formas que se encuentran en la facultad racional". La cuarta clase comprende las formas anteriores a éstas, donde el constituyente material es evidente.

El solitario concentrará todos sus esfuerzos en apartarse del elemento material y alcanzar la conjunción, ittiṣâl, con el entendimiento agente. La unión del hombre con este mundo superior es objeto de estudio constante por parte de Avempace, no sólo en este tratado, donde los términos "forma espiritual" e "inteligible" a veces se confunden. Uno de sus tratados lleva precisamente el título de Tratado de la unión del intelecto con el hombre, ${ }^{31}$ y Avempace lo escribió en los últimos años de su vida, después de componer el Régimen del solitario y la Epístola del adiós de manera que podemos suponer que refleja su doctrina más elaborada. El hombre no consigue la capacidad de pensar, fikrîya, más que alcanzando los inteligibles, ma 'qûlât. Los inteligibles no son las formas propias de las sustancias, resultan de las formas espirituales de ellas y tienen una entidad propia a la vez que relativa. Avempace contrapone la idea de caballo con la de un animal mitológico. La idea de caballo es un inteligible porque tiene relación con un ser real aunque su existencia como inteligible sea independiente, en cambio, la idea de un animal mitológico no es un inteligible, para Avempace. El inteligible está en una posición intermedia entre la forma espiritual y el objeto conocido:

Los objetos particulares con los cuales está vinculado el inteligible existente en un hombre determinado puede que desaparezcan, pero quedan sus formas espirituales - el inteligible está en relación con aquellas formas espirituales - y el hombre no entiende [los inteligibles] más que con ellas y en ellas. ${ }^{32}$

Dado que estas formas llegan al hombre a través de los sentidos y de la imaginación, que proporcionan otras formas inferiores, muchos identifican la forma espiritual de un objeto con su forma material, se lamenta, y no pueden entender lo que es un inteligible. El inteligible depende de la forma espiritual como de su

\footnotetext{
31 Editado y traducido, primero, por M. Asín Palacios, Al-Andalús, 7 (1942) 1-47 y traducido sobre nueva base mss. por Joaquín Lomba en Anaquel de estudios árabes, 11 (2000) 369-392.

32 Ed. Majid Fakhry (Beirut: Dâr an-nahar, 1968), p. 164.
} 
soporte, pero no es idéntico a ella, es como su manifestación autónoma en relación con el objeto, y el hombre lo capta a través de ella.

Tenemos, pues, la forma material en el objeto conocido, la forma espiritual en el sujeto cognoscente, y el inteligible entre las dos. El inteligible tiene una existencia propia y esto lo puede ver el filósofo, por ejemplo, cuando estudia la naturaleza, pues estudia los inteligibles no en cuanto tales sino "en cuanto son uno de los seres del mundo". La posición del filósofo de la naturaleza es intermedia entre la del hombre común, que vincula el inteligible con el objeto particular, y la del bienaventurado pues, en un tercer nivel, el hombre puede llegar a un inteligible desvinculado de cualquier forma espiritual. "El tercer nivel es el de los hombres felices que contemplan la cosa en sí misma".

La filosofía de Avempace tiene por esto una vertiente mística, aunque sea un misticismo basado en la ciencia y la razón. Es evidente que está en consonancia con todo el movimiento șûfí que se desarrolla en el Islam, movimiento que Algacel ayuda a legitimar, y que aspectos de la filosofía de Avicena también recogen. Seguimos sin saber qué obras filosóficas de Avicena llegaron a al-Andalús, a diferencia de su obra médica, el Qânûn fî t-țibb en latín, Canon, bien conocida y comentada. El caso de Algacel es mejor conocido, no sólo su obra principal, La revitalización de las ciencias de la religión, sino muchas más llegaron a al-Andalús. Los almorávides en un principio buscan su apoyo moral y más tarde queman sus obras, para contentar a los alfaquíes, - el principal enemigo fue Abû 'Abdallâh Ibn Hamdîn - y a los ash aríes. $^{33}$ Al contrario, los almohades dirán que el fundador de su movimiento, Ibn Tûmart, fue discípulo de Algacel y sabemos que sus obras fueron leídas y veneradas en este periodo.

Algacel fue discípulo de al-Fârmadhî (m. 1084), en lo que a la teoría y práctica del sufismo se refiere, aunque es cierto que su formación intelectual más fuerte es la del Kalam ash`arí, a través de otro maestro, Abû l-Ma`âlî al-Guwainî (m. 1085, antes mencionado). La vida de Algacel refleja las inquietudes de un espíritu profundamente religioso, que desea para sus correligionarios - y para sí mismo un bien fácil de comprender, pero difícil de explicar: el bien de la religión islámica, en sus creencias y prácticas.

Esta ansia de llegar al fondo de lo religioso explica su decepción frente a la dialéctica ash arí que expresa a veces en su obra más notable, Ihyâ' 'ulûm addîn, ${ }^{34}$ Revitalización de las ciencias de la religión. La obra está compuesta por cuatro secciones, cada una comprende 10 libros. La primera sección habla de las 'ibâdât, las obligaciones cultuales para con Dios. La segunda, de las 'âdât, usos o costumbres: alimentación, matrimonio, compras. La tercera se llama muhlikât, cosas que llevan a la perdición, es decir, vicios, aunque incluye un libro acerca de los "secretos del corazón". La cuarta, mungîyât, las cosas que salvan, las cuales se ordenan en maqamât: arrepentimiento, constancia, temor, pobreza, fe en Dios y

Darío Cabanelas, "Notas para la historia de Algacel en España", Al-Andalús 17 (1952) 223-232.

M. Asín Palacios reproduce parte de su contenido en su obra: La espiritualidad de Algazel y su sentido cristiano. Madrid, 1931-34. 
amor a Dios. Según este libro, todo lo que Dios ha creado se encuentra en la "tabla bien guardada", una reminiscencia de la tabla que guarda el Corán celeste (Corán 85: 22). Contiene las ideas eternas, de modo que los cuerpos sensibles no son más que copias. El corazón puede conocerlas, pero este corazón es distinto del órgano corporal, es "una sustancia sutil, divina y espiritual". Conoce de dos maneras: a través de los sentidos y directamente. El conocimiento directo es posible porque este corazón es como un espejo que puede reflejar las ideas de la "tabla bien guardada".

El lenguaje de Algacel está lleno de símiles, que nos llevan a un mundo distinto tanto del de la teología racional como del de la denostada filosofía helenizante: el mundo del sufismo. El corazón, una fina sustancia espiritual y divina, conoce no por vía del estudio y del razonamiento, sino "de la experiencia con fruición, del éxtasis y de la disolución". Sin embargo, el corazón del hombre debe hacer un esfuerzo para llegar a este nivel de percepción y en otros lugares, Algacel llama a los hombres para agudizar su oído, símil del órgano de percepción, y captar así el lenguaje de la creación: un lenguaje sin letras ni sonidos, es decir, un lenguaje no racional.

A pesar de ello, otras obras suyas - de otros momentos, anteriores testimonian su dominio de la teología racional musulmana o de los denominados fundamentos, $^{35}$ y nos asombra su capacidad de estudio y de redacción. Perfectamente ash`arí es su polémica contra la filosofía neoplatónica encarnada por Avicena, esto es el Avicena racionalista, pues obviamente la polémica tiene que efectuarse en un plano y lenguaje comunes, como son los de la teología racional y la filosofía. Considera que los filósofos no tan sólo son reos de infidelidad sino también son inconsistentes en sus pruebas, y de manera sistemática los ataca en la obra titulada La inconsistencia de los filósofos. ${ }^{36}$

El móvil que indujo a Algacel para escribir La inconsistencia de los filósofos fue, por descontado, religioso. Algacel reacciona contra ese pequeño grupo de gente, dice, que se cree superior a sus contemporáneos y que ha rechazado los mandamientos del Islam. ${ }^{37}$ Este grupúsculo, al que pertenecen filósofos como Avicena y Alfarabi, cultiva unas ciencias parte de las cuales es inocua: la lógica y la matemática, pero otra que atenta contra las verdades reveladas: la física y la metafísica.

Algacel acepta moverse en el terreno de sus adversarios y en 20 capítulos rebate las tesis que considera más características de estos herejes. Por ejemplo, que el universo es eterno tanto en el pasado como en el futuro, o las falsedades de los filósofos afirmando la génesis del universo por emanación del Uno, lo que lleva

\footnotetext{
35 Ver traducciones de algunas de ellas en M. Asín Palacios, El justo medio en la creencia, Madrid: Inst. Valencia de D. Juan, 1929.

${ }^{36}$ Tahâfut al-falâsifa, ed. M. Bouyges, Beirut, 1927; ed. S. Dunyâ. 6. ed. Cairo, 1980. Ed. bilingüe M. Marmura, Brigham Young Unniversity Press, Provo, 1997.

${ }^{37}$ Ed. Dunyâ, p. 73. Marmura, p. 1.
} 
a negar que Dios sea el agente y artífice del universo, o la negación que hacen los filósofos de los atributos divinos en cuanto distintos de su esencia, o la su incapacidad para probar que el alma humana es inmortal o que el cuerpo resucitará.

Hemos dicho que, sin embargo, los ulemas en tiempos de los almorávides quemaron sus obras, y se menciona incluso la Ihyâ', pero ya en vida, Algacel tuvo que hacer frente a acusaciones de infidelidad. En una de las obras traducidas por M. Asín, ${ }^{38}$ Algacel se defiende diciéndoles que la infidelidad no consiste en discrepar de la doctrina de alguna escuela, por ejemplo, la ash ‘arí. Quien sigue a uno de estos maestros, lo pone por delante del profeta. Los ash`aríes caen además en la contradicción "porque estos teólogos pretenden apoyar sus doctrinas en el razonamiento pero te exigen que no veas más que lo que ellos ven". Infidelidad es desmentir al profeta en alguna de las cosas que enseñó, y el texto revelado es suceptible de interpretación, en muchos casos. Es más, si la lectura literal desemboca en la absurdidad, hay que proceder a la interpretación del texto.

Algacel reconoce que los sufíes se lanzan a la interpretación alegórica con demasiada facilidad, pero mientras no se toquen los textos que expresan los principios de la fe, no se debe declarar infiel a ningún musulmán que abandone el sentido literal y opte por una alegoría. De esta manera, Algacel se protege de acusaciones de infidelidad por sus manifestaciones similares a los sufíes en varias obras, y como se ha dicho, en su obra principal, La revitalización de las ciencias del Islam.

El sufismo filosófico es un fenómeno que aparece también en Abû Bakr Ibn Ṭufayl que nació en Guadix - Wadî Âsh - hacia 1110 y estudió en Sevilla y Córdoba. ${ }^{39}$ Estas ciudades pasaron a poder de los almohades en 1147 y 1149, respectivamente, y su califa Abû Ya qû̉b Yûsuf no sólo hizo de él su médico personal, sino que también le tuvo a su lado como hombre de confianza. La vida de Ibn Țufayl, hasta su muerte en 1185, transcurre a la sombra de los califas almohades y no debía tener mucho tiempo para escribir. Aparte de un tratado de medicina inédito, sólo tiene una obra indiscutida: Historia de Hayy ibn Yaqzân. La obra conocida también por Libro de los secretos de la sabiduría oriental y traducida a menudo como El filósofo autodidacta, ${ }^{40}$ tuvo gran difusión desde que el profesor de árabe de Oxford, Pococke, en el siglo XVII, lo tradujera, con ese título, al latín. ${ }^{41}$

38 Tafriqa bain al-islâm wa-z-zandaqa, traducida en el apéndice $\mathrm{n}^{\circ} \mathrm{V}$, en El justo medio en la creencia, pp. 499-540.

39 Larry Conrad, ed. The World of Ibn Tufayl. Interdisciplinary Perspectives on Hayy ibn Yaqzân. Leiden: Brill, 1995.

40 Traducciones españolas, de F. Pons Boigues, reimpresa en Barcelona 1987, y de A. González Palencia, reeditada por Emilio Tornero, El filósofo autodidacta. Madrid: Trotta, 1995.

${ }^{41}$ Josep Puig Montada, "Abû Bakr Ibn Ṭufayl, a aventura da humanidade" en Ensaios de Filosofia Medieval no Islã. São Paulo: Editora Paulus, 2006. 
Observamos que el nombre había aparecido ya en Avicena, y en efecto, Ibn Tufayl no oculta su admiración por Avicena, así como por Avempace, de quien nos habla como primer representante del pensamiento realmente filosófico en la península. Conoce a Algacel, el enemigo de Avicena y de los filósofos helenizantes, pero Abentofail se muestra crítico sobre su obra anti-filosófica y muy reservado sobre su obra esotérica.

El argumento de la Historia de Hayy ibn Yaqzân es la evolución de un Robinsón, cuyo origen tiene dos versiones: según la primera, fue un niño abandonado en un arca; según la otra, hay una isla donde se produce la generación espontánea del hombre. La segunda es la versión preferida de Ibn Țufayl, el médico. El niño crece, alimentado por una gacela, y va desarrollando sus facultades. Un momento importante lo representa la muerte de la gacela. Hayy le hace una primitiva autopsia y descubre que el corazón es el centro vital, del que algo ha desaparecido, que debe ser una sustancia sutil y cálida. Su marcha ha ocasionando la muerte.

Los avances de Hayy comprenden el descubrimiento del fuego, de los tres reinos, de la composición de la sustancia en materia y forma, del alma como forma de los cuerpos animados. A los 28 años este "filósofo autodidacta" descubre el mundo incorruptible de los cielos y conoce la existencia de Dios como su creador, para estudiar luego su esencia.

No termina aquí el recorrido de Hayy. A través de la introspección, del examen de sí mismo, ve que posee una naturaleza espiritual cuya perfección consiste en la contemplación de Dios. A partir de ahí el filósofo se convierte en el sûfí que quiere abandonar el estorbo del cuerpo para llegar a la disolución del yo y perderse en la contemplación de Dios.

La alegoría comprende un tercera parte: la destinada a demostrar la harmonía entre la razón natural, Hayy, y la revelación, Abșâl. Abșâl es otro nombre empleado por Avicena para una pareja donde Abșâl es el espíritu contemplativo y su compañero Salmân, el hombre práctico. Abșâl llega a la isla y se encuentra con Hayy, a quien enseña el lenguaje. De sus conversaciones llegan a la conclusión de que cuanto Hayy ha descubierto con su razón coincide con todo lo que Abșâl ha recibido de la revelación.

Es posible que Ibn Țufayl haya recurrido a esta alegoría para afrontar la acusación que los teólogos ash aríes, y los alfaquíes, en general, levantaban contra los filósofos, pero no olvidemos que la respuesta viene en la tercera parte de la novela, y no es su núcleo. Su tesis principal es la capacidad de la razón humana para conocer el universo y acercarse a su Creador. Pero es cierto que los almohades, a cuyo servicio estaba Ibn Țufayl, respetaban la figura y la doctrina de Algacel, que acusaba a los filósofos de impíos y herejes y que el Kalam ash arí se oponía a los filósofos helenizantes por la misma razón. Esta acusación es frecuente, ni el propio Algacel se libró de ella, como hemos visto, y no por ello es menos peligrosa. 
Si Ibn TTufayl utilizaba la alegoría para dar esta solución, que supone la harmonía entre Corán y filosofía neo-platónica, su discípulo Averroes (1126-1198), prefiere la forma de un dictamen, que recuerda una fatwa: Libro decisivo del discurso y determinante de la conjunción (ittișâl) entre ley religiosa y sabiduría. ${ }^{42}$ Averroes atiende a una pregunta, si el estudio de la filosofía está permitido (mubâhn), prohibido, prescrito como recomendable o como obligatorio. Para contestar se apoya en la Revelación misma, y dice que la Revelación, previsora, ha establecido diversas maneras de llegar a la verdad, que se ajustan a las capacidades de las personas: unos son capaces de argumentos demostrativos, otros dialécticos, y otros retóricos, y la profecía se dirige a los tres tipos de hombres. Ya podemos imaginarnos que los filósofos son los que utilizan los argumentos demostrativos, silogísticos.

Los conocimientos obtenidos por ellos pueden referirse a materias de las que no trata la ley religiosa; en tal caso, no hay motivo de preocupación. Si se refieren a materias consideradas por esta ley, o bien coinciden con ella o bien difieren de su aspecto literal. También en este segundo caso hay posibilidad de coincidencia, recurriendo a la interpretación del texto. La interpretación, según su definición, consiste en "trasladar el significado de una expresión de su sentido primario a su sentido figurado, sin violentar la lengua árabe". Averroes está en la misma línea que Algacel, con el que discrepa en muchos puntos, pero no en éste, y así nos dice que siempre que aparece una contradicción entre la filosofía y el sentido literal del texto, éste admite la interpretación.

Como Ibn Țufayl, Averroes se ha educado en al-Andalús, ha visto hundirse a los almorávides y ha encontrado apoyo en los almohades, aunque a diferencia de su amigo este apoyo le faltará al final de sus días. ${ }^{43}$ Ahora bien, la sabiduría, la filosofía, para Averroes se diferencia en aspectos importantes, de la que presentaban Avempace y Abentofail. Si las ocupaciones políticas y los habían impedido a éstos dedicarse a una lectura y estudio detenidos de Aristóteles, no le ocurrirá esto a Averroes, a pesar de sus funciones de juez en Sevilla y Córdoba, y médico y consejero del sultán Abû Ya qûb Yûsuf (reinó 1163-1184). Averroes, animado por este califa, explicará y comentará los escritos aristotélicos, con excepción de la Política, que los árabes no conocían; en su lugar comentará la República de Platón. Su labor será tan decisiva que pasará a ser conocido en la Europa cristiana como el Comentador por antonomasia. Para comprender su esfuerzo, debemos tener en cuenta que Aristóteles aparece en la tradición islámica teñido fuertemente de neo-platónico. Se le atribuyen obras apócrifas, entre las

42 Fașl al-maqâl, edición princeps de MJ Müller, Munich, 1859, y múltiples ediciones. Traducción española de M. Alonso en Teología de Averroes. Comillas, 1947. Reimpresión Sevilla: el Monte, 1998.

43 Miguel Cruz Hernández, Abu-l-Walid Ibn Rusd (Averroes): vida, obra, pensamiento, influencia. Córdoba: Publicaciones de la obra social y cultural CajaSur, 1997. $2^{\text {a }}$ ed. 
cuales una Teología ${ }^{44}$ y un Libro del bien puro, la primera de las cuales es una adaptación de las Ennéadas IV, V y VI de Plotino, y la segunda de la Elementatio theologica de Proclo. 'Abd al-Lațîf al-Baghdâdî (m. 1231), autor de un comentario al Libro Lâm de la Metafísica, cita y resume este libro, considerándolo todavía aristotélico.

Además de estas confusiones, el sistema emanatista diseñado por al-Fârâbî y por Avicena muestra una solidez que hace difícil pensar en una alternativa. Es el sistema que Algacel expone en nombre de los filósofos: el mundo emana de Dios, identificado con el Uno, en un proceso que se inicia con un primer causado, que contiene en sí la dualidad y en ella el principio de multiplicidad, y que termina en el mundo de la materia. En su Epítome de metafísica. Averroes simpatizaba aún con esta explicación, pero en su réplica a Algacel, en el Tahâfut at-Tahâfut, que puede traducirse como "La inconsistencia de la Inconsistencia de los filósofos", se pronuncia definitivamente en contra de la doctrina de que del Uno emanan las diferentes esferas, los intelectos y la materia:

Todo esto no son más que invenciones que Avicena, Alfarabi y otros han forjado en contra de los antiguos [filósofos]. La verdadera doctrina de éstos es que existen solamente unos principios que son los cuerpos celestes, y que los principios de éstos... son sus motores. ${ }^{45}$

El abandono del emanacionismo no lo es también de todo resto de neo-platonismo. La Unidad como principio se mantiene en el sistema averroico y lo cohesiona como "la calor existente en cada ente deriva de la calor primaria". La unidad absoluta es causa tanto de la singularidad como de la multiplicidad de los entes, y todavía más es causa de existencia:

Según Aristóteles... todo aquello cuya existencia solamente se produce mediante unión de partes, como la unión de la materia y la forma, o la unión de los elementos del mundo, recibe la existencia a consecuencia de esta unión. ${ }^{46}$

Junto a esta componente neo-platónica, el sistema averroico debe responder a unas cuestiones que no aparecen en Aristóteles, y por tanto son otra componente no-aristotélica. El problema más conocido, y más trascendente, es la eternidad del universo, pues tal problema no se daba para Aristóteles: para él el mundo no puede ser más que eterno. Ya en el mundo helenístico se suscitó la polémica, y a Juan Filopón - un filósofo cristiano del s. VI - debemos varios argumentos destinados a probar la finitud del universo, es decir, que éste ha tenido comienzo y no puede ser eterno.

${ }^{44}$ Teología / Pseudo-Aristóteles; traducción del árabe, introducción y notas. Luciano Rubio Madrid: Ediciones Paulinas, 1978.

45 Edición de Maurice Bouyges, Tahafot at-Tahafot. L'incohérence de l'incohérence (Beirut, 1930; R 1987), p. 184. Traducción inglesa de Simon van den Bergh, Londres, 1954; R 1969. Trad. catalana parcial J. Puig Montada, L'ensorrament de l'Ensorrament (Barcelona: PAM, 2005), p. 187.

${ }^{46}$ Ed. Bouyges, p. 180; trad. Puig, p. 183. 
La discusión sobre la eternidad del mundo, que abre la obra, es la más importante y forma parte de una larga tradición polémica en torno a si Dios creó el mundo después de Su existencia, o el mundo es una creación natural y lógica de Dios. La tesis de los filósofos musulmanes resultaba de adecuar el pensamiento neoplatónico a la revelación coránica: así como de la bondad del Uno se producía la emanación de los demás seres, así Dios los crea y da existencia. No están diciendo que Dios no cree de la nada, sino que la existencia del mundo es un efecto de la acción divina, que no hay razón para retrasar.

$\mathrm{El}$ ataque de Algacel se produce mediante diversos argumentos, muchos ya empleados por sus antecesores en la polémica. Contra la tesis de los filósofos (Avicena y su tradición), de que el mundo no puede ser posterior a Dios más que en esencia, no en tiempo, puesto que el tiempo es algo creado - es la medida del movimiento del universo - Algacel tiene respuesta. La prioridad de Dios no es temporal, cierto, pero tampoco esencial entendiendo ésta como la prioridad de la causa sobre el efecto. Algacel traduce la creación del mundo, y con él del tiempo, en dos enunciados: primero, "existe $x$ y no existe $y$ ", segundo "existe $x$ y existe $y^{\prime \prime} ; x$ es Dios e $y$, el mundo con el tiempo. Nada nos hace introducir otro tiempo que conecte un enunciado con el otro, más que la imaginación. Ahora bien, y es limitado y tiene un principio, y así es posterior a Dios, como cualquier individuo es posterior a Dios.

H.A. Wolfson, al que sigue H. Davidson, ${ }^{47}$ denominan estos argumentos "de infinitudes" pues dicen que no puede haber infinitos cambios sucesivos sin uno primero, por ejemplo. Las causas no pueden formar cadenas sin un principio, al menos, y esto nos lleva a establecer que el mundo tuvo un inicio. Averroes quiere ser fiel a Aristóteles y hace una distinción entre infinito esencial o accidental. Averroes, con Aristóteles, está de acuerdo en que no puede haber un regreso infinito de causas y que hay una Causa Primera, pero ello no excluye lo que llama infinito accidental. ¿Qué entiende Averroes por infinito accidental? Es el infinito que aparece en las cadenas de seres y de actos.

Según los filósofos, esto se repite circularmente hasta el infinito, aunque es necesario por una Primera Causa. Así ocurre con la existencia de un hombre por causa de otro hombre... Si Sócrates engendra a Platón, el motor último en el momento de engendrarlo es la esfera, el alma, el entendimiento, o todos ellos o el Creador, y por esto dice Aristóteles: "Al hombre lo engendra otro hombre y el $\mathrm{Sol}^{\prime \prime}{ }^{48}$

La idea, pues, de Averroes es que los hombres son causa de otros en sentido accidental, no esencial. La intervención del Primer Motor es continua y esencial. Así no ver dificultades a una sucesión infinita (circular) porque es accidental; la verdadera conexión con el Primer Motor en cada momento no es accidental, es esencial y está limitada.

\footnotetext{
${ }^{47}$ Proofs for Eternity, Creation and the Existence of God. Oxford UP, 1987, pp. 336 ss.

48 Tahâfut at-Tahâfut, ed. Bouyges, p. 268.
} 
La respuesta de Averroes en este caso es comparable a la que también da contra Algacel en el tema que tratábamos más arriba: la anterioridad de Dios respecto del mundo, como argumento para explicar el origen limitado del universo. Avicena había entendido que se trataba de una prioridad no temporal, sino esencial, del orden de la causa que es anterior por esencia a su efecto (aunque sean simultáneos en el tiempo). Algacel objetava que la prioridad era esencial, pero basada en la singularidad de Dios, de un ser infinito sobre un ser finito.

Averroes no está dispuesto a aceptar la limitación temporal del mundo, sino sólo la espacial. El mundo es limitado en extensión, pero no su movimiento, y por tanto el tiempo. Pero la prioridad, también esencial, hay que buscarla en la naturaleza de Dios diferente de la del universo y su respuesta se basa en que Dios existe fuera del tiempo, mientras que el universo, por naturaleza, tiene que existir moviéndose, o sea en el tiempo. En el caso de lo que por naturaleza está unido al tiempo, la inexistencia precede a la existencia, y no es válida la comparación con la magnitud espacial.

Dios, que existe fuera del tiempo, precede a su creación con la prioridad de su esencia inmóvil y atemporal sobre un objeto creado, dependiente de Él y en movimiento. Averroes parte de su análisis de la naturaleza, de acuerdo con las pautas aristotélicas, y establece un Primer Motor cuya trascendencia define con ayuda de esta investigación física. El diálogo con Algacel es inviable y la antinomia de la razón, inevitable.

Junto con el estudio del universo y del proceso de la creación, el estudio del hombre y del proceso del conocimiento intelectual es otro pilar de la filosofía de Averroes. Analiza el proceso cognitivo desde la potencia sensorial hasta la racional, y habla de un proceso activo y otro receptivo-pasivo en el seno del alma racional. Por una parte, el proceso de adquisición de los conceptos es receptivo, algo que a Averroes le parece evidente, y su esfuerzo se centra, en demostrar que la formación del concepto o idea requiere una facultad activa. Es imposible que las formas recibidas de la imaginación puedan actuar sobre el entendimiento, si antes éste no ha procedido a despojarlas de su materia y a hacerlas inteligibles en acto. Es posible, sin duda, reconocer una facultad doble, pero Averroes va más lejos y pasa a hablar de dos sustancias. ¿Por qué razón? A causa de toda la tradición greco-árabe sobre el entendimiento agente y el entendimiento material.

La aportación de Averroes bien conocida está relacionada con el entendimiento material más que con el entendimiento agente, como ha señalado H.A. Davidson. ${ }^{49}$ Averroes evoluciona de una posición próxima a Alejandro de Afrodisia a otra cercana a Temistio, de modo que su concepción final del entendimiento receptivo es la de una sustancia no generada ni destructible, separable, simple y que no es pasiva en el sentido de padecer alteraciones. A

\footnotetext{
49 Alfarabi, Avicenna, and Averroes, on Intellect. Nueva York - Oxford: Oxford UP, 1992, en particular su capítulo "Averroes on the Material Intellect", pp. 258-314.
} 
pesar de ello, Averroes tiene que definirlo como "un cuarto género de ser", es decir, no es forma, ni materia ni su compuesto.

La otra sustancia existe en nuestras almas - en contra de la opinión de Alejandro de Afrodisia, para el que es exterior - es eterna, y está totalmente en acto. Es el entendimiento agente que "desnuda" las formas de la materia y las hace inteligibles Averroes habla a menudo del entendimiento agente como aquel que hace que las razones, significados - en latín intentiones - de las formas imaginadas pasen de ser motrices en potencia, a serlo en acto. Un ejemplo al que recurre en varias ocasiones es el de la luz, que hace que los colores pasen de la potencia al acto y puedan ser vistos, es decir, hagan mover:

Debes saber que la relación del entendimiento agente para con este entendimiento (material) es como la de la luz para con el diáfano, y la relación de las formas materiales para con él, es como la relación del color para con el diáfano. De la misma manera como la luz es la perfección del diáfano, así el entendimiento agente es la perfección del entendimiento material, y de la misma manera que el diáfano no es movido por el color ni lo recibe más que cuando está iluminado, este entendimiento no recibe los inteligibles que aquí hay más que si es realizado e iluminado por aquel entendimiento. Del mismo modo que la luz hace pasar el color de la potencia al acto, de modo que este pueda mover el diáfano, así el entendimiento agente hace pasar las intentiones materiales de la potencia al acto, de modo que el entendimiento material las recibe. ${ }^{50}$

Las intentiones pueden actuar sobre el entendimiento material porque ellas tienen una fuerza motriz que reciben del entendimiento agente. Son dos partes que hay en el alma, pero no explican ellas solas la realidad del entendimiento individual, aquel que es un hecho (factum). En Averroes, este entendimiento efectivo aparece asociado al entendimiento teórico (speculativus) y al entendimiento que está en disposición de actuar, el entendimiento in habitu. La acción de este último es extraer todos los inteligibles que queremos y actualizarlos después de estar en potencia. El término aparecía en Alejandro de Afrodisia, y Averroes está de acuerdo con él en que el entendimiento in habitu no es eterno y es el órgano intermedio para generar inteligibles.

En cuanto al entendimiento teórico, Averroes lo define como aquel que el entendimiento agente pone en el entendimiento material, igual que "el artesano pone las formas artificiales en los artefactos". Ocupa pues un estadio intermedio entre agente y paciente, y por esto es asimilable al entendimiento in habitu, como Averroes mismo indica. El entendimiento teórico es nuestro tesoro de conocimientos, de inteligibles existentes en acto pero no es el punto final, ya que los filósofos aspiran al conocimiento de los inteligibles en sí mismos, no como intentiones ni formas imaginadas, sino abstractas de toda materia. Podemos ir

50 Commentarium magnum, ed. F.S. Crawford (Cambridge, Mass. 1953), c. III.5, p. 410: 11. 688-703. Traducción española en "Averroes: Comentario mayor al libro Acerca del alma de Aristóteles", Anales del seminario de Historia de la Filosofía 22 (2005) p. 86. El diáfano es el medio que la luz activa, y es propio del aire, de la luz y de algunos sólidos, siguiendo una doctrina aristotélica. 
extrayendo inteligibles de los distintos niveles de formas, pero no podemos proceder de manera infinita, sino que nuestro conocimiento debe culminar en una forma abstracta o separada de la materia, en una "una quididad que no tiene quididad" en deuda con Avempace. Se trata de saber qué entendimiento es capaz de ello.

$\mathrm{Su}$ respuesta es una forma compuesta del entendimiento in habitu y del entendimiento agente. El entendimiento material no podía unirse directamente al entendimiento agente ni el teórico tampoco es capaz, pero es condición necesaria para el conocimiento de las cosas abstractas. El entendimiento agente es ahora la forma determinante de un compuesto, el cual a su vez es nuestra forma última (forma postrema), y nuestra perfección. Su posición no está libre de dudas que el mismo Averroes reconoce y afronta para considerar, finalmente, que se resuelven por una interpretación 'analógica' de la relación entre materia y forma, a saber, pues la materia es lo menos perfecto, en este caso el entendimiento teorético, y la forma es lo más perfecto, el entendimiento agente. Los instrumentos de análisis que le proporciona la tradición aristotélica llegan a sus límites y solamente puede emplearlos de manera analógica, algo que ya hemos visto hacía al definir el entendimiento material. Sería erróneo atribuir a Averroes divisiones rotundas en sustancias independientes, cuando el mismo reconoce los límites de la investigación diciendo:

En general, cuando uno examina el entendimiento material junto con el agente, estos se le presentan como uno solo, en un aspecto, y como dos, en otro. Son dos en cuanto a las maneras de actuar: la acción del entendimiento agente es engendrar [formas inteligibles], la de este, ser "in-formado". Son uno en cuanto el entendimiento material llega a su perfección por obra del entendimiento agente y lo entiende. Por esto decimos que en el entendimiento unido a nosotros se manifiestan las dos facultades, una del género activo, otra del pasivo. ${ }^{51}$

Las reflexiones de Averroes suscitaron vivas discusiones en el mundo latino, y también en el hebreo, pero en el mundo islámico su influencia fue escasa. Una razón de peso fue la prohibición de la filosofía por el sultán almohade Abû Yûsuf Ya qûb (reinó 1184-1199) en 1197, pero también jugó en contra de Averroes la desaparición física de al-Andalús - Córdoba fue conquistada por Fernando III de Castilla en 1236 - y el declive del Maghreb. Los filósofos árabes puede que utilizaran sus materiales, pero se distanciaban de él por precaución, como hizo Ibn Sabeîn (1216-ca. 1269), en Ceuta. ${ }^{52}$ Ibn Sab în conocía a Averroes, pero precisaba que la adoración ciega que Averroes sentía por Aristóteles no le permitía ver sus errores. Ibn Sab în creyó encontrar la verdad en la doctrina sufí como lo refleja en

51 Commentarium magnum, ed. Crawford, c. III.20, p 450: 213 - 451: 222. "Averroes: Comentario mayor", p. 92.

52 Anna Ayșe Akasoy, Philosophie und Mystik in der späten Almohadenzeit. Die Sizilianischen Fragen des Ibn Sab în. Leiden: Brill, 2006, con abundante bibliografía. 
su principal obra "Lo que es indispensable al gnóstico, y credo del que conoce y está más cerca de la Verdad". ${ }^{3}$

La preferencia de Ibn Sabeîn por el sufismo es sintomática. El sufismo tiene una recia tradición en al-Andalús, que se puede remontar a Ibn Masarra (antes citado); poco antes de Ibn Sabeîn vivió 'Abbâs Ibn al-'Arîf (1088-1141), y contemporáneo suyo es Ibn al- ‘Arabî (m. 1165-1240) que murió en Damasco. ${ }^{54}$ Uno diría que el Islam occidental sintió el sufismo como su auténtica filosofía.

Nacido también en Córdoba, unos años más tarde que Averroes, en 1138, o 1137, era Maimónides. ${ }^{55}$ Moisés era hijo de Maimón, juez rabínico de la ciudad, que todavía estaba en poder de los almorávides. En 1147 los almohades entraron en Córdoba y la familia del dayyân huyó - se dice - a Almería para escapar de la persecución religiosa de los seguidores del mahdi Ibn Tûmart pero la ciudad cayó en sus manos en 1157. Seguro es solamente que en 1159 la familia se encontraba ya en Fez. Allí se instalaron en lo que ahora se llama Fâs al-Bâli, la ciudad más vieja, y se supone que figuraban como musulmanes.

Moisés Maimónides se integró totalmente en la cultura científica árabe y también en la islámica, por ejemplo, en su historia. Maimónides se interesó pronto por la ciencia de origen griego. Estudió con el hijo del astrónomo Gâbir Ibn Aflâh de Sevilla y con discípulos de Abû Bakr Ibn Bâgga (1085/90-1139) que había muerto en Fez en 1139. En filosofía estudió todos los autores de la tradición helenística y árabe, con una admiración especial por Aristóteles

Sin embargo, el principal objeto de su estudio fueron la Mishnah Torah, el Talmud y la profecía. Su "antepasado" Yehuda Ha-n-Nassi del siglo II había compilado la Mishnah, el código de prescripciones legales conservado hasta entonces de forma oral. El Talmud, en cambio, no tiene decisiones precisas sino discusiones y disquisiciones para que el "estudioso" llegue a una conclusión. Maimónides se propuso redactar un comentario de la Mishnah para acceder directamente a ella, sin necesidad de utilizar el Talmud. Maimónides empezó a trabajar en su comentario, en árabe, a la Mishnah antes de llegar a Fez.

Ahora bien, en 1163 murió el sultán ‘Abd al-Mu'min, le sucedió Abû Ya`qûb Yûsuf, el protector de Averroes, y la persecución antijudía se disparó. Un amigo de la familia, Yehuda Ibn Shaushan fue torturado hasta morir por negarse a convertirse. Moisés Ibn Maimûn estuvo a punto de correr la misma suerte, pero un amigo, el teólogo Ibn Muwashsha le defendió y salvó. La familia decidió emigrar y, de noche, el padre, Maimon, y sus dos hijos, Moisés y David, huyeron de Fez a

53 Ibn Sab'în, Budd al- 'ârif wa- 'aqîida al-muhaqqqiq al-muqarrib, ed. Georges Kattura, Beirut, 1978.

${ }^{54}$ El Islam Cristianizado. Estudio del sufismo a través de las obras de Abenarabi de Murcia. Madrid: Plutarco, 1931, 2aㅡ ed. Madrid: Hiperión, 1981.

William C. Chittick, The Sufi Path of Knowledge: Ibn 'Arabî's Metaphysics of Imagination. Albany: SUNY, 1989.

Claude Abbas, Ibn 'Arabî ou La quête du Soufre Rouge. París: Gallimard, 1989.

55 La bibliografía maimonideana es inmensa. El estudio más exacto de su vida y obra es: Herbert A. Davidson, Moses Maimonides. The Mand and his Works, Oxford University Press, 2005. 
Ceuta, donde embarcaron la noche del 18 de abril 1165 (4 Iyar 4925) hacia San Juan de Acre. En el viaje seguía trabajando en su comentario a la Mishnah. La ciudad estaba bajo la autoridad de los cruzados y así Maimónides entra en contacto con el cristianismo y con los cristianos.

Después de visitar Jerusalén y las tumbas de los patriarcas en Hebrón, la familia Maimónides terminará en Egipto, que en aquellos momentos mantenía buenas relaciones con el reino cristiano. La familia se instaló en Alejandría, donde murió su padre (en 1166). La ciudad sufría las guerras entre los Ayyubíes y Fatimíes. Maimónides seguía trabajando en su gran comentario a la Mishne Torah, escrito en árabe. El prólogo es conocido por los Ocho capítulos, donde Maimónides afirma que no va a ser original, sino a recoger lo que han dicho tanto los sabios en los Midrashot, en el Talmud, como los filósofos; los Aforismos de alFârâbî son su fuente más importante para la filosofía.

Terminó el comentario a la Mishneh Torah ${ }^{56}$ el año 1168 en Fusțât, el viejo Cairo, al sur de la nueva ciudad, al-Qâhira (fundada por los Fatimíes en 969). Este mismo año, el sultán Fatimí no pudo pagar el tributo al rey cristiano de Jerusalén y Amaury invadió Egipto. El sultán al- 'Adịd (1167-1171) ordenó a la población de Fustâtt refugiarse en El Cairo y quemar Fusțâț. Los Ayyubíes desde Damasco acuden en ayuda de los Fatimíes, y Saladino se convierte en el gobernador efectivo del país. Cuando en 1171 muere el último califa Fatimí, Saladino le sucede y reinstaura la ortodoxia suní.

Ya en dicho año 1168, Maimónides empezó a escribir su propio comentario a la ley, su Mishneh Torah, que terminó después de 12 años de trabajo en 1180. El primer libro es el del conocimiento, y su primera sección es la del "fundamento de la Torah" de la que tenemos la traducción española de Cohen de Lara. ${ }^{57}$ Trata del conocimiento de Dios como Causa Primera, de sus atributos, y de la revelación a Moisés en el Sinaí. Los israelitas no creían en Moisés por causa de sus milagros, sino por la escena del Sinaí y después del Sinaí, todos los israelitas se han convertido en testigos de la revelación.

Su hermano David murió en un naufragio en el Océano Índico en 1177 y Moisés tuvo que asumir la responsabilidad de alimentar la familia, y para ello se dedica a la medicina, donde destaca también por sus obras escritas. En 1187 Saladino llamó a la guerra santa contra los cruzados y reconquistó Jerusalén. Maimónides estaba en contacto con al-Fâdil, el visir de Saladino, que le nombró médico de la corte. Ahora Maimónides está ocupado en escribir la Guía de los

${ }^{56}$ Mishnah 'em perush R. Moshe ben Maimon. Commentary on the Mishnah. Edición del texto árabe y traducción al hebreo moderno por Josef Käfih, Jerusalén, 1963-68. Reprint 1988. 7 vols. 3 tomos.

Tratado de los artículos de la ley divina. David Cohen de Lara, trad. Amsterdam 1652. Lisboa, 1925. Barcelona: Río Piedras, 1991. 
descarriados que terminará en $1190{ }^{58}$ donde va a unir la Biblia con la filosofía de Aristóteles.

En su primera parte interpreta términos bíblicos fundamentales: por ejemplo,

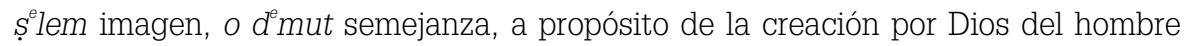
a su imagen y semejanza. Algunos creían que Dios tenía figura de hombre por ello, pero Maimónides interpreta que se refiere a su capacidad intelectual, y explica así los atributos divinos, a destacar el de la incorporeidad de Dios. En la tercera, Maimónides se esfuerza en dar una explicación racional de los preceptos mosaicos.

La segunda parte es la más sistemática, y por lo demás, refleja un buen conocimiento de Aristóteles. Maimónides enumera 26 proposiciones de los peripatéticos "para demostrar la existencia, unidad e incorporeidad de Dios", y la $\mathrm{n}^{\circ}$ XXV establece que es un motor. La XXVI afirma que el tiempo y el movimiento son eternos, y que existe un cuerpo sujeto a un movimiento eterno, punto con el que M. no está de acuerdo.

A la vez Maimónides trata de la constitución del universo. En cuanto a la emanación, define ésta como la acción de la inteligencia separada "que no opera por contacto ni a determinada distancia" (c.12). Sin embargo, Maimónides sostiene la creación temporal del universo (II. Cc. 13-22) y distingue al respecto tres teorías: 1ำ la de la Ley de Moisés, "Hacedor del cielo y de la tierra (Gen. 14: 22) de la nada y el tiempo con él, $2^{\circ}$ la de Platón, y $3^{\circ}$ la de Aristóteles (c. 13), estos dos a partir de la materia. Maimónides entiende que Aristóteles no se pronuncia sobre la eternidad del mundo, pues no presenta una demostración (c. 15) como pretenden los seguidores, piensa que "todo esto no es susceptible de demostración".

II. 16. Digo pues tocante a las afirmaciones de aquellos mutakallimíes que pretenden haber demostrado la creación temporal del mundo, que no admito sus pruebas... Asimismo lo que Aristóteles y sus seguidores afirman a favor de la creación temporal no constituye una prueba decisiva... quiero hacer prevalecer la teoría de la creación sobre la de la eternidad.

Si Maimónides se opone a la doctrina de los filósofos musulmanes sosteniendo la eternidad del mundo, no es porque los textos bíblicos así lo indiquen. Maimónides entiende que la doctrina de la eternidad del mundo implica la absoluta necesidad en la naturaleza y la exclusión de los milagros, en los que debemos creer. En cambio la doctrina de la creación temporal del mundo da plena satisfacción al carácter auténtico de la religión mosaica.

Por esto Maimónides se preocupa en demostrar la autenticidad de la revelación y a diferencia de otros pensadores judíos anteriores, insiste en el carácter único de la profecía de Moisés. Maimónides tiene especial cuidado en

58 Dalâlat al-hấinîn, ed. y traducción francesa de S. Munk, París, 1856-66. 3 vols. Reprint, Osnabrück, 1964. Traducción hebrea, Moré nevukhim, de Shemuel Ibn Tibbon, Jerusalén, 1960. A partir de la versión hebrea, David Gonzalo Maeso hizo la traducción española. Madrid: Editora Nacional, 1983. 
probar que la revelación que Moisés recibió es muy distinta de las que recibían los demás profetas, y que no debe estar teñida por la imaginación. La ley promulgada a Moisés no es ninguna visión alegórica, pues "Moisés no recibía las revelaciones en forma de enigmas, sino en una visión en que le aparecía la clara realidad" (Ciencia, I.7.6). La idea de una relación directa se repite en lo que se considera la introducción a Mishneh Torah:

Y si las profecias de los otros, eran emboçadas en figuras, y enigmas, por la revelacion ser por medio de Angel, el varon de Dios, Moseh, inmediatamente y sin interposicion alguna, según dize: vocalmente, hàblo con el. ${ }^{59}$

La tentación para los seguidores de Maimónides era interpretar la revelación de Dios a Moisés en términos de comunicación intelectual, y más de uno así lo hizo. Los discípulos de Maimónides formaron una verdadera escuela, especialmente activa en el condado de Provenza y en la Corona de Aragón. La recepción de Maimónides también despertó el interés por la filosofía aristotélica, que promovió las traducciones y el estudio de los comentarios de Averroes.

A lo largo de la exposición precedente, el lector habrá reconocido tres corrientes principales del pensamiento andalusí: la teológica, del Kalam, representada por Ibn Hazm; la esotérica, donde el sufismo ocupa el lugar primordial, y la filosófica, de origen greco-helenístico, representada por Avempace, Averroes y Maimónides. La comunicación entre ellas existe, a menudo en forma de polémica, pero a veces en forma de síntesis, y no es casual que el ejemplo más conocido del pensamiento andalusí sea precisamente una obra donde se combina el pensamiento filosófico con el místico, y se defiende la coincidencia de la Ley revelada con la razón, me refiero a la Epístola de Hayy Ibn Yaqzân.

59 Ciencia, I.7.6. MAIMÓnides. Tratado de los artículos de la ley divina (nota 54), VII.7, p. 33, e insiste "Y vision, y no con enigmas". 